\title{
Integrated Energy Solution towards Sustainable Isolated Communities
}

\author{
G. Hejazi, C. Wimmler, E. de Oliveira Fernandes, M. A. Matos, and S. R. Connors
}

\begin{abstract}
Since any activity requires energy, access to energy is an essential means for all. Especially isolated communities in developing countries often have no or limited access to affordable energy resources. Yet, more than 1.5 billion people do not have the possibility to use electricity and around 2 billion people also rely on premier resources such as dung and wood for heating and cooking. It is often those premier resources that cause indoor air pollution and health problems. Besides, the minimum level of energy needs can frequently not be reached.

An integrated approach for isolated communities to improve access to energy and increase the level of health and well-being in housing will be presented. Housing and other physical elements and conditions of such communities will be analyzed so that sustainable livelihoods can be achieved. Thereby the needs and opportunities for the enhancement of housing and living in general have to be balanced. In the end, planning for sustainable livelihoods requires an integrated framework to guarantee sustainable development and growth.
\end{abstract}

Index Terms-Energy access, energy planning, intermediate and renewable energy technologies, sustainable development.

\section{INTRODUCTION}

The motivation of this research is to respond to the "energy for all" leitmotiv and discuss the problematic of how to conceive integrated energy solutions at isolated village-level. Merit is placed on an 'integrated concept' to support local decision makers with more adequate solutions to provide energy to fulfil both electric and thermal needs, based on available local resources and taking advantage of the recent technology developments.

The concept is intended for isolated communities (e.g. hilly settlements, forest fringes or islands) with poor financial conditions that are unlikely to be grid connected due to the enormous distances among them and limited access to modern fuel. At the same time, the lack of literacy and the high poverty levels force most inhabitants of these areas to use

Manuscript received June 14, 2015; revised September 9, 2015.

G. Hejazi and C. Wimmler are with the Faculty of Engineering, University of Porto, INEGI - Institute of Science and Innovation in Mechanical and Industrial Engineering, and INESC TEC - INESC Technology and Science (formerly INESC Porto), Porto, 4200-465 Portugal (e-mail: golnar.hejazi@fe.up.pt, c.wimmler@fe.up.pt).

E. de Oliveira Fernandes is with the Mechanical Engineering Department University of Porto, and INEGI - Institute of Science and Innovation in Mechanical and Industrial Engineering, Porto, 4200-465 Portugal (e-mail: eof@fe.up.pt).

M. A. Matos is with the Electrical Engineering Department, University of Porto, and INESC TEC - INESC Technology and Science (formerly INESC Porto), Porto, 4200-465 Portugal (e-mail: mam@ @e.up.pt).

S. R. Connors is with the MIT Energy Initiative, Massachusetts Institute of Technology, Cambridge, MA 02139-4307, USA (e-mail: connorsr@mit.edu). whatever resources and conversion devices are available. Sustainability and the attenuation of current indoor pollution problems have to be addressed in this context. This research is an attempt to discuss and come about with proposals on the topic where many opportunities are waiting for decision makers to take the most appropriate decisions.

\section{ENERGY ISSUE AND SUSTAINABLE DEVELOPMENT}

The energy issue is a widely discussed theme that is associated with a wide variety of problems as, for instance, availability of resources, conversion technologies, security of supply, cost, environmental impact etc. Though, three basic aspects have to be assessed in the context of energy issues: the energy resources which are itself an integral part of the environment, i.e. energy has the same type of positioning regarding environment as water, for instance, both are environmental resources; the purpose of the energy which is to aim for well-being and sustainable development, which necessarily includes the social and economic development; and the technology capabilities to exploit the natural energy resources converting them into accessible, manageable, storable, clean, safe as well as economically affordable final and useful energy products.

Since the core of most long-term energy plans and strategies is focused on sustainable development, it is worth recalling that sustainable development has been defined in 1987 in 'Our common future' as the development that satisfies the needs of the present without compromising the ability of future generations to satisfy their [1]. The quest for sustainability comprises economic prosperity, social responsibility and environmental stewardship, whereas economic vitality, social equity and environmental equity are aimed for without jeopardizing the environmental conditions (climate changes causing islands flooding or other dramatic modification of the living conditions).

\section{ENERGY REQUIREMENTS}

In our times it is not conceivable that energy to cover all essential services for survival and well-being of the whole communities including the most isolated and remote communities is not yet achievable for billions of people in least developed countries (LDCs) (Fig. 1) [2]. The matter has to be addressed in a holistic way. The energy services for those communities might be clustered in households, community and production activities where households most probably represent the highest energy consumers. The dominant energy service is cooking while space heating and cooling are barely used [3]. Instead there is need for some 
electricity for lighting and a few apparatus. In general, the energy demand for community activities is rather small, with the most common services being schools, medical, religious or social community centers. Energy needs for production activities are mainly associated with the specific local conditions and the availability of farmland, livestock and agricultural activities [4], [5] which might include graining, grinding or crushing, whereas most of these processes use natural power (humans or animals) or, in exceptional cases, energy in the form of diesel powered systems. From all aspects presented above special consideration should be placed on electricity availability for communications, lighting and cooling (freezer) as well as on clean modern fuels for thermal uses.

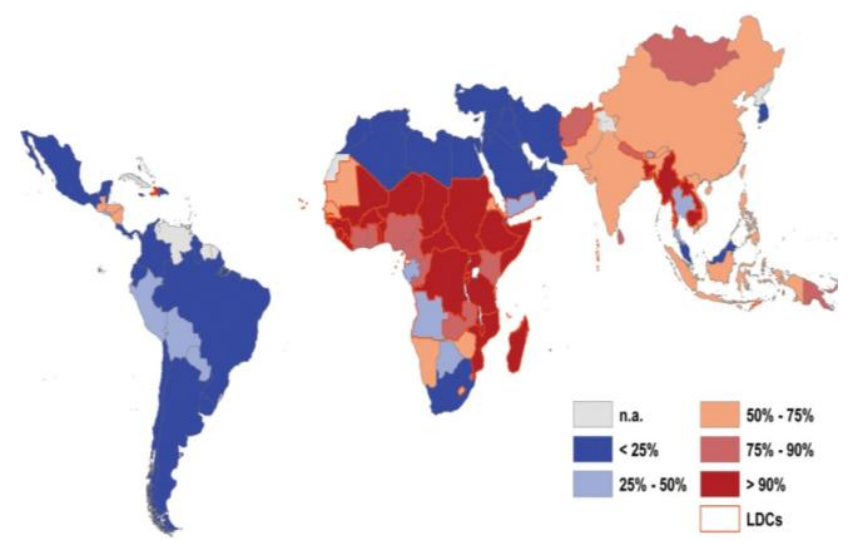

Fig. 1. Share of population without access to modern fuels for developing countries, 2007.

\section{ENERGY SUPPLY}

The traditional energy sources used to be solar, of course, through the most natural means (radiation and temperature) as well as wood and dung. Around 100 years ago a wider access began developing. Fossil fuels such as diesel and bottled gas emerged in connection with some mechanization of the agriculture and support for some commercial activities (storage, transportation of goods, etc.). The access to renewable energy technologies started developing only in the last 50 years with the initiative of several international cooperation bodies. Common applications include windmills to pick up water, solar driers and cookers and more recently solar PV panels for schools, communication and teaching aids However, access to modern affordable technologies still could not be reached, making diesel, wood and other burning materials the dominant energy resources, all of them being cause for poor indoor environmental conditions.

Nonetheless, with the time, the technological evolution has led to new supply possibilities. Modern technologies are more and more accessible and due to the proportionated dimensions they can be adapted by small human settlements. Thereby, different supply systems, decentralized, intermediate or dispersed ones, could be applied within communities.

A decentralized energy system or cluster of small systems is a viable alternative at the isolated community level and may cover either the entire community, or comprehend small and micro scale systems to cover specific services within the community. It shall be clarified that energy systems are not just the dedicated conventional technological systems but buildings themselves, as PLEA teaches and practices, are to be considered here as energy systems as well. For the latter, various technical, financial, social and environmental aspects should be considered for technology selection, i.e. income level of consumer, ease of maintenance, technology adoption or adaptation to climate and climate change [6]. The constraints regarding the financial support, however, may induce the option for other solutions of much smaller scale. In any case, from the planning point of view the approach of an integrated system must be present.

In 1960 Schumacher introduced the concept of intermediate technologies which represents an appropriate solution when it becomes too expensive to apply larger-scale technologies [7]. Intermediate technologies respond to isolated needs, reduce the dependency on fossil fuel imports and mineral resources, they are clean and do not pollute or poison the environment, they consider people over profit, and they are low to medium cost as well as labor-intensive [8], [9]. Some common intermediate and improved technologies are: improved cooking stoves, pot-in-pot evaporator as cooling reserve, treadle pump, multi-function platform, vane-flapping wind converter, etc. Despite still using fossil fuels (in most cases), intermediate technologies reduce issues of indoor air pollution and health significantly [10].

More recent ways of supplying energy at a very small scale and for specific services within a household or community are renewable based systems such as portable or pico-/micro-scale technologies, with the most common ones being portable PV devices (solar Tuki), pico PV system, classical solar home system, thermal collectors, etc.

\section{Challenge of AdAPtIVE ENERGy TECHNOLOGIES}

Although each of the above described systems could exist on its own, it is the combination that leads to a successful sustainable solution. Hence, challenges arise to adequately dimension supply scenarios for communities, whereas the proper conditions of use and management have to assure the usage of those technologies and protect the environment and health.

When evaluating implemented renewable energy projects various market failures were revealed [11], [12] i.e. lack of proper use and management and maintenance and spare parts; misallocation of investment leading to inappropriate infrastructure [13]; divergence of interests between different actors involved, implementation "too much too soon" [14] and so on.

Yet there are three other major concerns when dealing with renewable energy technologies once they are chosen or to be chosen: financing, intermittency of resources and diversity in supply. Since the potential supply solutions are often of very small dimension, it is not the cost itself but the feasibility of projects that cannot pay for themselves as the users by both or either their small number and low economic capacity do not have the economic capability to pay for enough energy to justify such investments. In addition, the management of intermittent resources, which may be a path to facilitate this type of systems/services, is very difficult, especially when there is no alternative for back-up and the community has to 
rely on polluting resources again. Similar accounts for the diversity of supply. Little improvement is given to a community if, for instance, only all electric services can be covered from modern technologies and at the same time still premier resources are used to cover thermal requirements.

In order to minimize the above challenges emphasis should be placed on successfully adopting conditions for modern energy technologies with sufficient educational, technical and financial support [15].

Besides the variety of challenges a considerable lack of energy solutions and planning at village and block level could be identified [16]. An integrated approach to supply all energy requirements in a sustainable manner and thus lead to better indoor environmental conditions is highly required.

\section{PROPOSED APPROACH}

An appropriate structure of context involves careful assessment, especially as changes and adjustments of the solution are more difficult once the decision has been implemented [13]. A review of multi-criteria decision support methods highlighted that it is essential to have a simple, understandable and user-friendly approach of the system [17], [18]. In the following sections the conceptual along with a systematic framework will be presented and discussed.

\section{A. Conceptual Framework}

A conceptual framework, representing the overall energy system within the objectives of the energy triangle, is illustrated in Fig. 2. The core of this framework is simplified by a village, which could be any isolated community. Hence, it is initially proposed to identify the current energy carriers in use. Then the conditions in and around the village have to be assessed, whereas village demography and topography as well as resource availability are key aspects to focus on. Critical reflection should also be placed upon the availability of land, the influence of extreme weather events (i.e. if annual monsoons lead to local floods) or the possibilities of connecting to the outside world. Especially the latter aspect can demonstrate a village's reliance on certain imported energy sources (i.e. kerosene, diesel or paraffin). Additionally, the evaluation of resource conditions requires an assessment of the availability of abundant resources. Certainly, there would be no interest to assess the possibilities of a wind turbine, if wind is not available for longer periods during the year. Similar accounts for hydro power, which in most cases is scarcely available all around the year and, thus, may compete with other uses such as agricultural activities.

The second phase of the conceptual framework focuses on social elements, which include stakeholders, local government and businesses as well as production activities. All of those elements contribute in shaping the physical conditions of the village. Hence, the acceptability and adaptability of modern energy systems within the village have to be analyzed. Opposition against modern technology or the favoring of a specific technology solution can become considerable obstacles for the implementation of some systems. Consequently, education about and introduction to modern technologies become a key factor before any implementation. In addition, local decision makers should receive the necessary support when making decisions that affect the long term future of the community.

The framework continues with a focus on boundary constraints. As such, physical and social elements limiting the performance against the energy objectives have to be assessed. Commonly analyzed constraints should include: land, water, wind, wood, solar radiation, availability of energy reserves, geographic setting and climate, security of supply, economic growth in the community, etc. All of the boundary constraints fall under the umbrella of the energy triangle, whereas it is intended to provide and increase energy access considering economic development in an environmentally sustainable manner.

Along those elaborations the conceptual framework sets the scene when planning to improve energy access in isolated communities. It is clear that not all aspects can be evaluated or assessed. Nevertheless, decision makers can be supported in understanding the complexity of making decisions and how to select modern energy technologies to supply the respective energy requirements. Thereby, emphasis is placed on designing solutions that improve the performance of the overall community, rather than a specific household or service. Only with the diversity of supply alternatives threatening indoor air pollution and health issues can be overcome.

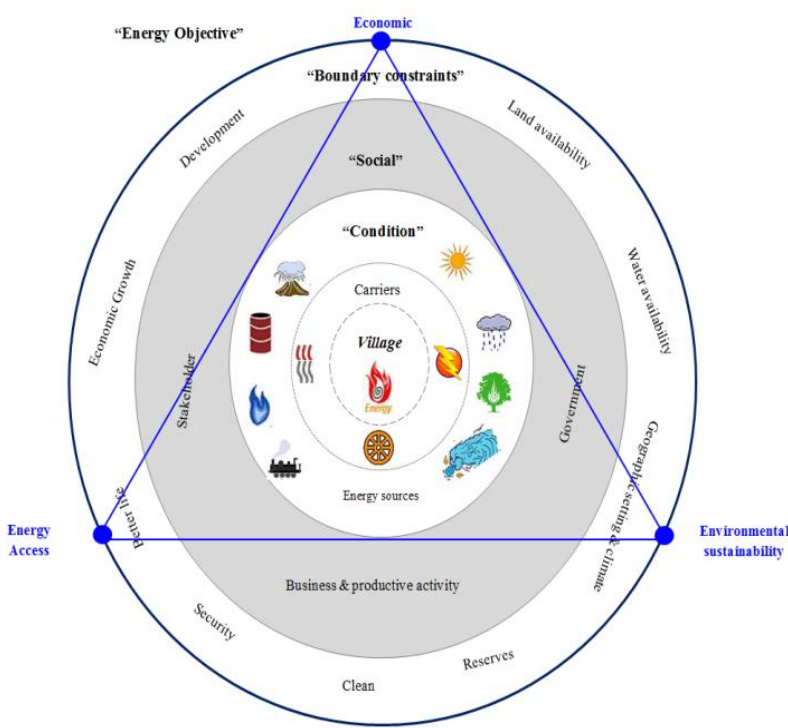

Fig. 2. Conceptual energy framework modified by author [19].

\section{B. Systematic Approach}

Now, to apply the concept in the case of isolated communities, a systematic integrated approach (Fig. 3) can assist describing each of the different stages of a successful sustainable energy operation.

1) The priority goal is energy and environment for people. The direct service to the people must be clear. It has not been rare in the past to have factories working in isolated areas not contributing to help providing means of more and more qualified energy to the populations living nearby. Consequently, the initial stage must identify the problems and issues associated to the exploration of the energy resources and their services to the people in the area, their housing, community buildings, information, education, etc. and, of course, support for the economy. This includes at all stages the environmental concerns 
mainly indoor air pollution and its health impacts caused by the current energy resources in use, but also the indiscriminate use of resources leading to the depletion of woodland, fuel scarcity as well as the type and dimension of local resources used (i.e. wood again or water with other competing uses) [20].

2) The energy challenges are the environmental context, both outdoors and indoors; the extension and the level of the needs and of the energy resources that will be made available to respond to the former and the technologies that can be afforded. Here the differentiation among the different types of energy services is particularly relevant: lighting, heating, drying, cooling (freezing), mobility, etc. and the corresponding selection of technologies that will allow for providing those services. For instance, passive technologies may represent a first step to fulfill proper indoor comfort conditions before thinking of another type of energy to be used. Yet, the technology has evolved a lot in what regards the understanding of the passive technology potentialities. Even, if through the use of very basic concepts and approaches.

Additionally, traditional ways of using renewable energy resources rather than modern energy technologies, which could be used elsewhere, have to be highlighted. Such examples include usage of daylight [21], drying food in the sun, building or using natural occurring shading, place pollutant cooking stoves outside the house, etc. It is of utmost importance that the pathway to sustainable development does not lead through solely increasing energy access, but to increase the level of comfortability. The predominant health issues, as a result of inappropriately using energy resources and modern technology [22] have to be overcome.

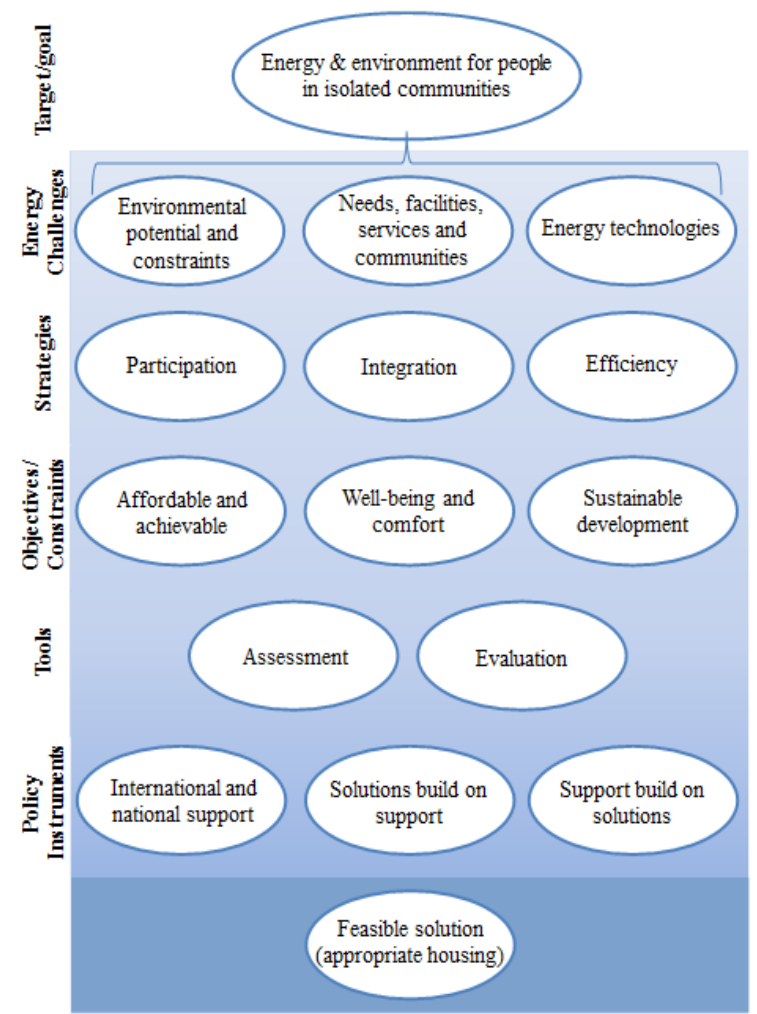

Fig. 3. Systematic approach for energy access (own illustration).

3) Strategies must aim at an integrated energy approach. The different strategies require the participation of all end users, providing them proper information and arguments for their motivation, mobilization and commitment to achieve successful outcomes and increase the energy usage in a more effective and sustainable manner. Besides the social integration there is a need for a coherent integration of different potential energy systems based on criteria of exergy and appealing to storage and intermittence of the service, if that would be the case. All in all, for economic and environmental reasons and to take as much advantage of the integrated system as possible the concern with the energy efficiency must be present at all stages. With proper energy solutions and planning three main correlated benefits will arise for isolated communities: 1) improvement of living level, 2) development of agriculture and 3) saving in wood and agricultural waste that causes less deforestation as well as more equity and health in life [23]. Rather than always focusing on the newest and most modern technologies, potential energy solutions should also consider replacing, improving or increasing mitigation procedures. The herein presented integrated solution aims at reducing indoor air pollution and increasing energy access and comfort level of life.

4) Balancing objectives and constraints. From the variety of technical, economic, environmental and social aspects the integration process must be the preferred one. Economically sustainable solutions require being affordable, realistic, in a timely manner, achievable and with the low overall impacts. Thus, three main complementary goals are to be pursued by a project: affordability bearing in mind external support; sustainability in terms of global environment but also in social and economic terms, i.e. not excluding anybody.

Yet, discussions still focus too much on selecting the renewable energy technology that shall be used to generate electricity. The fact is that the selection process is much more comprehensive as different end-uses require different energy carriers. Adequate decision support to cover all end-use services is obligatory. One of the major drawbacks of an approach driven by one or by a limited number of technologies is the difficulty of overcoming the majority or even all challenges at ones. Indeed, it does not seem in the interest of an isolated community to have access to modern energy and thus only cover a few services with those technologies, whereas many other services still have to be covered from pollutant energy carriers. Therefore, a balanced solution that combines different levels and sizes of technological development is much more beneficial.

5) Tools for the assessment and monitoring shall be used to evaluate and manage the solutions and the system(s). That shall bear in mind the eventual dominant energy users such as housing and communitarian buildings. Since households are the most representative energy use sector within such isolated communities, the further considerations will primarily focus on housing.

The dominant energy needs within households imply cooking, hygiene (i.e. hot water), food preservation and storage, communication, shading, heating and cooling. However, not all of these services are essentially to be covered from energy technologies. Heating and cooling, for 
instance, are very much subject to climate and architecture. In fact, adaptive behavior might be a key aspect, especially in terms of sustainable development. While tropical or warmer climates could make use of naturally occurring shading as well as ventilation through the building structure, cooler climates require better levels of building insulation or additional layers of clothing. In both cases, energy is not necessarily a prerequisite. Passive architecture of buildings can significantly contribute to manage heating and cooling requirements, and thus lead to high comfort and well-being within the building without necessitating additional energy resources.

6) Search for financial mechanisms and support. Proper design and contextual documentation is needed. It has not been uncommon to have projects lying down in the shelves of the receiving countries, often elaborated by dedicated institutions to aid or just to finance energy projects for the last 20 years or so. The missing of an integrated approach and the resulting inadequacy to the local context in all those cases then led many projects to never be implemented. Hence, good projects, well thought, balanced and justified are a sine qua non condition for obtaining appropriate financing. Information on support mechanisms, regulations and policies can be useful complementary instruments for the whole process, especially to avoid gaps or delays in the implementation process.

\section{CONCLUSION}

This research illustrates the completeness and richness of an integrated process when searching for energy solutions for isolated communities with no or limited access to energy networks from national grid systems or others. It also highlights the importance and the way to be adopted when dispersed energy systems or decentralized energy systems have to be considered appealing to the combination of intermediate and renewable energy technologies at different sizes and scales. This integrated approach appears to open up a compromise between the difficulties of financing infrastructure of large areas of the globe where over 1 or 2 billion people still rely on premier resources and the need to respond in an economic, reliable and sustainable manner. Moreover, it is expected that with a more accurate understanding of methods and approaches as well as the progress on available energy technologies and solutions, local decision makers can contribute to increase the energy access to more sustainable vectors not only from a local point of view but also from a global perspective. It is the combination of energy planning with architectural, spatial and economic planning that leads to sustainable development. In the end, energy and environment are for all.

\section{ACKNOWLEDGMENT}

The authors acknowledge the support of the Portuguese Foundation for Science and Technology (FCT) in the frame of the individual doctoral research grant by the FCT scholarship SFRH/BD/92812/2013 as well as support by the research teams from the MIT-Portugal Program (MPP), INESC
Technology and Science (INESC TEC) and the Institute of Science and Innovation in Mechanical and Industrial Engineering (INEGI).

\section{REFERENCES}

[1] United Nations World Commission on Environment and Development, Our Common Future (Brundtland Report), Oxford University Press, Oxford, 1987.

[2] UNDP and World Health Organization, "The energy access situation in developing countries," UNDP and World Health Organization, New York, 2009.

[3] K. Narula, Y. Nagai, and S. Pauchari, "The role of decentralaized distributed generation in achiving universal rural electrification in South Asia by 2030," Energy Policy, vol. 47, pp. 345-357, 2012.

[4] FAO, "How to feed the world in 2050, background paper for the high-level forum on how to feed the world in 2050," FAO, Rome, 2009.

[5] GIZ, "Modern energy services for modern agriculture: A review for smallholder farming in developing countries," GIZ, Eschborn, Germany, 2011.

[6] A. Kemmler, "Regional disparties in electrification of India do geographic factors matter? working paper No.51," Centre for Energy Policy and Economics, Zurich, 2006.

[7] R. Varma, "E.F. schumacher: Changing the paradigm of bigger is better," Bulletin of Science Technology \& Society, vol. 23, no. 2, pp. 114-124, 2003.

[8] A. Akubue, "Appropriate technology for socioeconomic development in third world countries," The Journal of Technology Studies, vol. 26, no. $1,2000$.

[9] R. Wicklein, "Designing for appropriate technology in developing countries," Technology in Society, vol. 20, no. 3, pp. 371-375, 1998.

[10] World Health Organization, "Health in the green economy, co-benefits to health of climate change mitigation, housing sector, Executive summary," World Health Organization, Geneva, 2011.

[11] J. Cherni, I. Dyner, F. Henao, P. Jaramillo, R. Smith, and R. Font, "Energy supply for sustainable rural livelihoods, A multi criteria decision support system," Energy Policy, vol. 35, pp. 1493-1504, 2007.

[12] J. Kruger, "Towards an appropriate framework for South African rural renewable energy provision (dissertation)," University of Stellenbosch, Stellenbosch, 2007.

[13] N. Van Beeck, "A new decision support method for local energy planning in developing countries," University of Tilburg, Tilberg, 2003.

[14] D. Ghosh, P. Shukla, A. Garg, and P. Venkata Ramana, "Renewable energy technology for Indian power sector. Mitigation potential and operational strategies," Renewable and Sustainable Energy Review, vol. 6, pp. 481-512, 2002.

[15] A. Trappey, C. Trappey, G. Lin, and Y. Chang, "The analysis of reneweable energy policies for the Taiwan Penghu island," Renewable and Sustainable Energy Reviews, vol. 16, pp. 958-965, 2012.

[16] R. Hiremath, S. Shikha, and N. Ravindranath, "Decentralized energy planning: modeling and application: A review," Renewable and Sustainable Energy Reviews, vol. 11, pp. 729-752, 2007.

[17] P. Korhonen, H. Moskowitz, and J. Wallenius, "Multiple criteria decision support - A review," European Journal of Operational Research, vol. 63, pp. 361-375, 1992.

[18] K. Genova, V. Vassilev, F. Andonov, M. Vassileva, and S. Konstantinova, "A multicriteria analysis decision support system," presented at International Conference on Computer Systems and Technologies, Compsystech, Rousse, Bulgaria, 2004.

[19] World Economic Forum, "The global energy architecture performance index report 2013," World Economic Forum, Geneva, 2012.

[20] World Health Organization, "Addressing the links between indoor air pollution, household energy and human health," World Health Organization, Geneva, 2000.

[21] J. Balcomb, "Integration of heating, cooling and daylighting," presented at the Sixth International PLEA Conference Porto, Portugal, July 27-31, 1988.

[22] F. Fardeheb, "Appropriate architecture for the arab population of the Miditerranean basin: In search $\mathrm{f}$ a regional identity," presented at the Sixth International PLEA Conference Porto, Portugal, July 27-31, 1988.

[23] P. Catania, "China's rural energy system and managment," Applied Energy, vol. 64, pp. 229-240, 1999. 


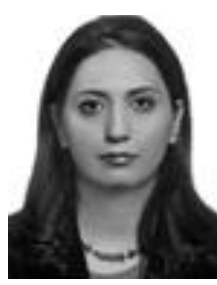

G. Hejazi graduated from Iran University of Science and Technology with a BSc. in industrial engineering in 2001 and from Newcastle University with a MSc. in renewable energy enterprise and management in 2011 Currently she is undertaking her $\mathrm{PhD}$ in the sustainable energy systems MIT Portugal Program at the University of Porto, Portugal. Prior to Newcastle, she has worked for several years in the Farayaz Material Engineering Research Center and the Material and Energy Research Center. Her special fields of interest include managerial aspects of renewable energies and planning of sustainable energy systems in remote areas.

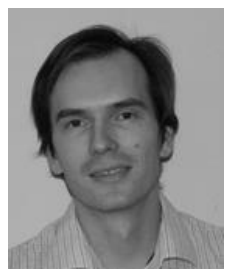

C. Wimmler is pursuing his $\mathrm{PhD}$ at the University of Porto, Portugal, in the sustainable energy systems MIT Portugal Program. His special fields of interest include renewable energy technologies, energy planning, policy and management as well as isolated energy systems. He graduated from the University of Applied Science Kufstein, Austria, with a BA in European Energy Business in 2010. In 2011 he received a MSc with distinction in renewable energy enterprise and management from Newcastle University, United Kingdom.

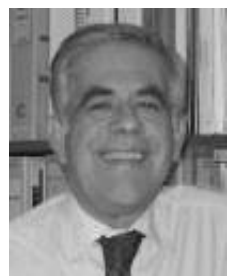

E. de Oliveira Fernandes is a full professor at the Faculty of Engineering, University of Porto, Portugal. He obtained his $\mathrm{PhD}$ on applied sciences at the Federal Institute of Technology (Lausanne, Switzerland) in 1973. Devoting the last 30 years of his career to teaching, research, consulting and public activities on various topics related to energy and environment, he was the founder of a RTD group on building thermal physics with major pioneering activities in Portugal on passive solar technologies in buildings, indoor air quality, and energy and environment in the urban space.

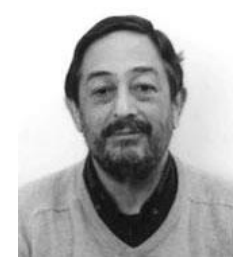

M. A. Matos was born in 1955 in Porto, Portugal. He received the El.Eng., Ph.D., and aggregation degrees. $\mathrm{He}$ is with the Faculty of Engineering of the University of Porto (FEUP) since 1978 (a full professor since 2000). He is also a coordinator of the power systems unit of INESC TEC. His research interests include classical and fuzzy modelling of power systems, reliability, optimization, and decision-aid methods.

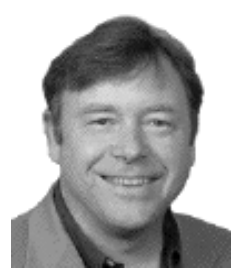

S. R. Connors is the director of the analysis group for regional energy alternatives (AGREA) part of the M.I.T. Energy Initiative (MITEI). AGREA's primary research focus is in strategic planning in energy and the environment, with an emphasis on the transformation of regional energy infrastructures (e.g. "energy pathways") to simultaneously address energy security, climate change, and other energy challenges. As an extension of his role as director of AGREA, Mr. Connors also coordinates several international energy initiatives involving MIT. Mr Connors is a founding board member of the U.S. offshore wind collaborative, and has served on the editorial boards of wind engineering and sustainability science. 